\title{
Neural responses to morphological, syntactic, and semantic properties of single words: An fMRI study ${ }^{\text {is }}$
}

\author{
Matthew H. Davis, ${ }^{\mathrm{a}, *}$ Fanny Meunier, ${ }^{\mathrm{a}, \mathrm{b}}$ and William D. Marslen-Wilson ${ }^{\mathrm{a}}$ \\ ${ }^{a}$ MRC Cognition and Brain Sciences Unit, Cambridge, UK \\ ${ }^{\mathrm{b}}$ CNRS Laboratoire Dynamique du Langage, Lyons, France
}

Accepted 2 December 2003

\begin{abstract}
Dissociations in the recognition of specific classes of words have been documented in brain-injured populations. These include deficits in the recognition and production of morphologically complex words as well as impairments specific to particular syntactic classes such as verbs. However, functional imaging evidence for distinctions among the neural systems underlying these dissociations has been inconclusive. We explored the neural systems involved in processing different word classes in a functional Magnetic Resonance Imaging study, contrasting four groups of words co-varying morphological complexity (simple, monomorphemic words vs complex derived or inflected words) and syntactic class (verbs vs nouns/adjectives). Subtraction of word from letter string processing showed activation in left frontal and temporal lobe regions consistent with prior studies of visual word processing. No differences were observed for morphologically complex and simple words, despite adequate power to detect stimulus specific effects. A region of posterior left middle temporal gyrus showed significantly increased activation for verbs. Post hoc analyses showed that this elevated activation could also be related to semantic properties of the stimulus items (verbs have stronger action associations than nouns, and action association is correlated with activation). Results suggest that semantic as well as syntactic factors should be considered when assessing the neural systems involved in single word comprehension.
\end{abstract}

(C) 2003 Elsevier Inc. All rights reserved.

Keywords: Language; Semantic processing; Lexical processing; Syntactic class; Nouns; Verbs; Adjectives; Morphology; Inflection; Derivation; fMRI; Temporal lobe; Frontal lobe

\section{Introduction}

An important question in understanding the cognitive and neural basis of language processing concerns the representation of different word types in the brain. Recent years have seen evidence for a number of neuropsychological dissociations that suggest neural separation of the

\footnotetext{
We would like to thank our volunteers for their participation, the staff of the Wolfson Brain Imaging Centre, University of Cambridge for their help with data acquisition, Matthew Brett, Rik Henson, and Ian Nimmo-Smith for advice on image processing and statistical analysis, Alexis Hervais-Adelman for assistance in collecting the action post-test data, Mike Ford and Ingrid Johnsrude for advice and guidance and Jay Rueckl, Steven Small, and an anonymous reviewer for comments on previous versions of the manuscript. This work was supported by the Medical Research Council of the UK.

${ }^{*}$ Corresponding author. Fax: +44-0-1223-359-062.

E-mail address: matt.davis@mrc-cbu.cam.ac.uk (M.H. Davis).
}

systems involved in processing different classes of words. For instance, considerable evidence now suggests that nouns and verbs can be differentially impaired follow brain injury (see for instance Caramazza \& Hillis, 1991; Damasio \& Tranel, 1993). Other dissociations have been reported between tasks involving morphological simple words (like jump or dark) and words composed of multiple morphemes (such as jumped, darkness Marslen-Wilson \& Tyler, 1997; Marangolo et al., 2003).

One interpretation of these dissociations is that this neural separation reflects core linguistic distinctions between mechanisms of word storage and grammatical processing (Pinker, 1999; Ullman, 2001). For instance, dissociations between verbs and nouns may arise as a consequence of the greater complexity of the grammatical information that is required for verbs to be used (Shapiro \& Caramazza, 2003). The comprehension of verbs may therefore place a greater demand on neural 
systems involved in grammatical operations than do nouns, hence the vulnerability of verbs following brain injury reflects specialisation for grammatical processing operations. Similarly, since polymorphemic words may be decomposed during identification (Caramazza, Laudanna, \& Romani, 1988; Marslen-Wilson, Tyler, Waksler, \& Older, 1994) additional processing operations for decomposition may occupy a distinct neural locus, damage to which may impact on the recognition of polymorphemic words (Tyler et al., 2002; Ullman et al., 1997).

An alternative account of these dissociations suggests that these deficits are a consequence of the different phonological and semantic properties of these classes of words. For instance, nouns tend to have more concrete meanings than verbs. An apparent verb impairment may arise from a greater difficulty in processing abstract words following brain injury (Bird, Howard, \& Franklin, 2000), though this remains controversial (Shapiro \& Caramazza, 2003). In accounting for dissociations involving morphologically complex words it has been proposed that regularly inflected words might depend more strongly on systems involved in phonological processing-for instance, due to the greater phonetic complexity of inflected forms (Bird, Lambon Ralph, Seidenberg, McClelland, \& Patterson, 2003). These proposals therefore suggest an alternative, non-grammatical account of impaired performance on verbs and morphologically complex words in brain-injured patients.

Functional neuroimaging investigations have an important role to play in assessing these contrasting explanations of the representation and processing of different word types. However, a flurry of work in recent years has not led to any consistent conclusions concerning the neural systems that are differentially activated by nouns and verbs. For instance, while some studies have reported regions of distinct activation in the posterior middle temporal lobe for verbs compared to nouns (Kable, Lease-Spellmeyer, \& Chatterjee, 2002; Perani et al., 1999) other studies have failed to replicate these results (Tyler, Russell, Fadili, \& Moss, 2001). One possible factor in explaining these discrepancies may be a linguistic difference between stimuli in languages such as Italian (as in the Perani study) that are marked with inflectional endings specific to verbs and stimuli in English which are typically uninflected and are therefore ambiguous between nouns and verbs (for instance, the unmarked stem walk may be either a noun or a verb).

Prior neuroimaging work that has investigated the processing of morphologically complex words (Beretta et al., 2003; Jaeger et al., 1996; Marangolo, Piras, Galati, \& Burani, 2003) have focussed on assessing the neural correlates of the overt morphological operations involved in producing complex forms from bare stems (though see Laine, Rinne, Krause, Teras, \& Sipila,
1999). These studies are of interest in demonstrating neural systems that may be involved in performing these morphological operations. However, these studies are not sufficient for us to conclude that these same mechanisms of overt morphological manipulation are damaged in patients that show a deficit in processing morphologically complex words. Evidence for neuropsychological deficits on complex words can be observed in tasks such as reading aloud (Rastle, Tyler, \& Marslen-Wilson, 1999), semantic (Longworth, 2002) or repetition priming (Marslen-Wilson \& Tyler, 1997) that do not necessarily involve overt morphological manipulation. It is therefore unclear whether the neural systems activated in these neuroimaging studies provide an adequate explanation of morphological deficits observed in neuropsychological populations. Considerable evidence has been amassed in the psycholinguistic literature to suggest that complex words are automatically decomposed into their constituent morphemes during non-morphological tasks such as lexical decision (Marslen-Wilson et al., 1994; Rastle, Davis, Tyler, \& Marslen-Wilson, 2000). It is therefore of interest to ask whether there is a unique neural signature of the processing of morphologically complex words during tasks that do not invoke overt morphological operations.

In this study we investigate the neural correlates of the semantic processing of single words that vary in morphological complexity and syntactic class. We used fMRI to investigate the effect of these two factors and their interaction on the neural processes engaged when reading single, English words in a synonym monitoring task. This task requires equivalent and highly demanding semantic processing for all words irrespective of morphological complexity or word class, but without contamination from overt behavioural responses on critical trials (as in lexical decision) or specifically morphological operations (as in generation tasks).

\section{Method}

\subsection{Participants}

We scanned 12 neurologically normal, right-handed, native-English speakers between 18 and 40 years of age. Informed consent was obtained under the supervision of the Addenbrooke's Hospital Local Research Ethics Committee. Data from one volunteer was removed due to excessive movement $(>3 \mathrm{~mm}$ displacements during each scanning run). A single scanning run from another volunteer was lost due to experimenter error.

\subsection{Behavioural task and procedure}

To ensure semantic processing of each word, we used a one-back synonym-monitoring task in which partici- 
pants read single words presented on the screen and pressed a button if the current word was related in meaning to the immediately preceding word. One synonym target was presented every 12 words (on average), such that participants had to read and understand each word in the list, even though they made very few detection responses. The baseline task was matched to the test task for stimulus and response characteristics and required participants to respond to letter identity in strings like 'fffff' and 'gggggg' that were matched in length to the word trials and presented at the same rate as the words (Devlin et al., 2002). Participants had to detect the occasional (1 in 12) trials on which the current stimulus contained the same letter as the immediately preceding string.

Words and letter strings were back-projected onto a video-screen placed outside the scanner bore. An angled mirror inside the head-coil allowed participants to read the words clearly and comfortably at a viewing distance of approximately $60 \mathrm{~cm}$. Target-detection responses were made on an MR-compatible button-box held in the participants right-hand. Stimulus presentation and response measurement was controlled using DMDX software (Forster \& Forster, 2003).

Each stimulus (words and letter strings) was displayed for $1 \mathrm{~s}$ with a $1.5 \mathrm{~s}$ ISI ( $2.5 \mathrm{~s}$ SOA). Items in each condition (words or baseline) were grouped into 6 item blocks lasting $15 \mathrm{~s}$. These 6 conditions ( 4 word conditions, baseline and an additional rest block) were pseudo-randomly ordered with a different presentation order used for each subject. Each condition occurred 6 times in each scanning run.

\subsection{Word materials}

To create the two by two crossing of morphological complexity (simple vs complex) with syntactic class (verb vs non-verb) we selected four sets of 72 words from the CELEX database (Baayen, Pipenbrook, \& Guilikers, 1995), see Appendix A for a list of stimuli. Our choice of stimuli was limited by the number and type of morphologically complex words that are available in English, a language in which inflectional para- digms apply predominantly to verbs and derivational suffixes are primarily used to create nouns and adjectives. The two sets of verbs were either morphological simple (uninflected) or inflected with one of the three inflectional endings that apply to English verbs (-s, -ed, and -ing). The majority of words chosen occurred only as verbs in the database, though for all items, verb frequency was considerably greater than the summed frequency of all other forms of the same word. The two sets of verbs were matched on word-form frequency, imageability (taken from the MRC Psycholinguistic database, (Coltheart, 1981) supplemented by local norms where necessary) and length in letters (see Table 1). There was a small difference in the number of syllables in the words (inflected words had more syllables), though this was of only marginal significance $(p<.1)$.

These sets of simple and inflected verbs were matched to sets of simple and derived non-verbs. To create a contrast between derivational and inflectional morphology, we matched the set of inflected verbs to a set of morphologically complex words formed using productive derivational affixes (e.g., -able, -y, -ness, as defined by Marchand (1969)) all of which had a transparent semantic relationship with their stems (assessed using semantic-relatedness ratings cf. Marslen-Wilson et al., 1994). Since derivational endings commonly form adjectives, these derivationally complex words were a mixture of nouns and adjectives. They were matched to a set of morphologically simple nouns and adjectives that were equated for length (in letters and syllables), imageability and word-form frequency (all differences between verbs and non-verbs were $p>.1$ ). Note that, because the complex forms averaged two syllables and 7 letters in length, the simple forms tended to be phonologically complex, although always without any apparent morphological structure. Within each of the four sets of words, 6 pairs of words were selected that were either synonymous (e.g., monarch/sovereign) or closely related in meaning (scrounge/scavenge) to serve as targets for the semantic monitoring task. For the inflected verbs and derived words synonym pairs were chosen that did not have the same morphological ending (e.g., flaunts/ boasting, offender/guilty).

Table 1

Properties of items in the four experimental groups, mean $(S D)$

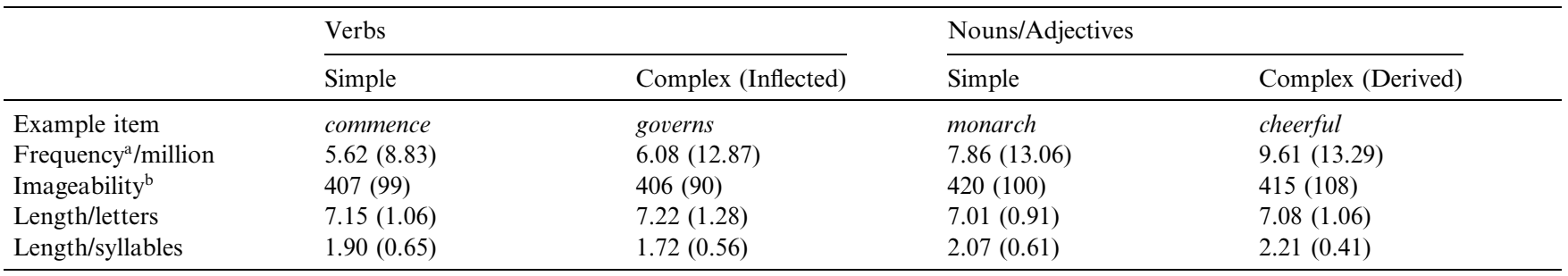

100, low imageability; 700, high imageability.

a Taken from the CELEX word-form database (Baayen et al., 1995).

${ }^{\mathrm{b}}$ Taken from the MRC psycholinguistic database (Coltheart, 1981). 


\section{4. fMRI data acquisition and analysis}

Echo-planar imaging data was collected on a 3-Tesla Bruker Medspec scanner, with a TR of $3.02 \mathrm{~s}$ during which $21 \times 4 \mathrm{~mm}$ axial-oblique slices were acquired with a $1 \mathrm{~mm}$ inter-slice interval. The field of view was $25 \mathrm{~cm}$ and matrix size $64 \times 64$ producing an in-plane resolution of approximately $4 \times 4 \mathrm{~mm}$. Two $9 \mathrm{~min}$ runs (186 scans/ run) were collected from each volunteer. The initial 6 volumes of each scanning run were discarded to allow for T1-equilibration.

EPI data was analysed using Statistical Parametric Mapping software (SPM99, http://www.fil.ion.ucl.ac.uk/). Data was realigned to the first (non-discarded) volume of the first run to correct for subject motion, images were corrected for differences in slice-acquisition time using sinc interpolation, normalised to an EPI volume based on the MNI template and resliced into $3 \times 3 \times 3 \mathrm{~mm}$ voxels. Regions of signal dropout in the anterior temporal lobe (Devlin et al., 2000) were masked during the normalisation process to minimise geometric distortion (Brett, Leff, Rorden, \& Ashburner, 2001). The resulting EPI volumes were smoothed with a $12 \mathrm{~mm}$ FWHM Gaussian filter suitable for a random-effects analysis (Xiong et al., 2000).

Data from each subject was entered into a general linear model using an event-related analysis procedure (Josephs \& Henson, 1999; Mechelli, Henson, Price, \& Friston, 2003). The five event types (four word classes and baseline) were supplemented by events for correctly detected semantic targets, detected letter targets, and for false-alarms (occasions when participants pressed the button to non-target events). Each of these eight event types were modelled with a canonical haemodynamic response function (Friston et al., 1998) with additional columns coding for temporal and dispersion derivatives to compensate for variation in timing and duration of the evoked response (Henson, Price, Rugg, Turner, \& Friston, 2002). Movement parameters obtained from the realignment stage of preprocessing were added as covariates of no-interest. A high-pass filter (120 s cut-off) and AR1 correction for serial auto-correlation was used. Contrasts of parameter estimates from the least-mean squares fit of this model in each subject were entered into a second-level analysis with subjects as a random effect (testing whether these contrasts differed from zero). Significant effects will be reported where they pass a whole-brain 'false-discovery rate' (FDR) correction for multiple comparisons at $p<.05$ (Genovese, Lazar, \& Nichols, 2002). Voxels that pass a moderately conservative uncorrected threshold $(p<.001)$ will also be presented, but interpreted with caution given the likelihood that they are false-positives produced by multiple comparisons.

\section{Results}

\subsection{Task performance}

Participants performed the synonym and letter detection task accurately, detecting $80 \%$ of the semantic targets and $98 \%$ of the letter string targets, a reliable
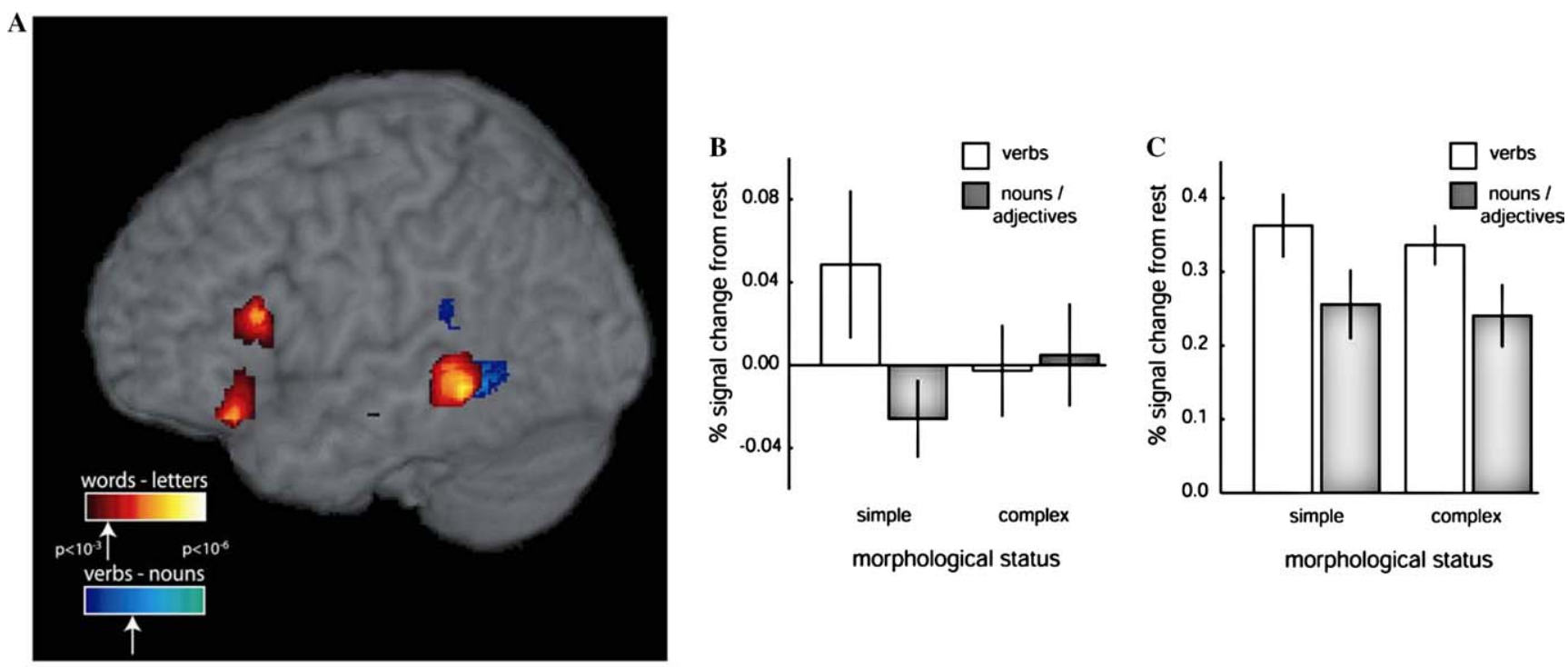

Fig. 1. (A) Activation images for words vs baseline (red) and verbs vs nouns (blue) rendered onto a canonical T1 MR image. The arrow ( $\uparrow$ ) on the $p$ scale shows the approximate threshold for each activation to pass False Discovery Rate (Genovese et al., 2002) corrected significance at $p<.05$. (B) Mean signal change from rest (peak of the fitted haemodynamic response function) for each condition in a left-insula voxel $(x=-30, y=-6$, $z=+18$ ) that showed an interaction between syntactic class and morphological complexity. Error bars show one standard error of the mean after between-subject variance has been removed, suitable for repeated-measures comparisons (Loftus \& Masson, 1994) (C) Left posterior middle temporal gyrus response $(x=-54, y=-48 ; z=-6)$ to the four word conditions relative to rest plotted as in $\mathrm{B}$. 
Table 2

Location and significance of peak voxels reaching $p<.05$ FDR corrected for the contrast of words versus letter string baseline

\begin{tabular}{lrrrr}
\hline Location & \multicolumn{2}{l}{ Coordinates } & \multirow{2}{*}{$Z$-score } \\
\cline { 2 - 3 } & \multicolumn{1}{c}{$x$} & \multicolumn{1}{c}{$y$} & \multicolumn{1}{c}{$z$} \\
\hline Left posterior middle & -63 & -42 & -3 & 4.48 \\
$\quad$ temporal gyrus & & & & \\
Left anterior fusiform gyrus & -45 & -42 & -12 & 3.74 \\
Left anterior cingulate cortex & -6 & 27 & -42 & 4.33 \\
Left inferior frontal gyrus & -48 & 30 & -15 & 4.24 \\
$\quad$ ventral) & -33 & 27 & -12 & 3.83 \\
Left inferior frontal gyrus & -48 & 24 & 18 & 4.21 \\
$\quad$ (dorsal) & -18 & -9 & -15 & 4.15 \\
Left hippocampus & 9 & 27 & 42 & 3.82 \\
Right anterior cingulate & 33 & -12 & 60 & 3.69 \\
Right premotor & & &
\end{tabular}

difference in performance $(t(11)=4.83, p<.001)$. Synonym detection accuracy did not differ between any of the four word conditions (all $p>.05$ ).

\subsection{Words vs baseline}

The contrast of all word events compared to baseline events revealed reliable left-hemisphere activation in frontal and temporal lobe regions known to be involved in lexical and semantic processing of visually presented words (see Fig. 1A). In particular, a large activation cluster was observed in left posterior temporal lobe. Although the peak activation (see Table 2) falls within the middle temporal gyrus, the area of activation included a peak voxel in an anterior region of the fusiform gyrus that has been described as forming a "visual wordform area' (Cohen et al., 2000; Cohen et al., 2002; Fiebach, Friederici, Muller, \& von Cramon, 2002; Polk \& Farah, 2002) though other authors have proposed a lessspecifically linguistic function for this region (see, for instance, Price, 2000; Price \& Devlin, 2003). As with the fusiform, there remains a considerable debate concerning the dominant function of the posterior middle temporal gyrus region activated in this contrast. However, recent demonstrations that both lexicality and semantic priming can influence activation in this region are consistent with a role for this region in semantic processing of written (Fiebach et al., 2002) and spoken words (Kotz, Cappa, von Cramon, \& Friederici, 2002).

We also observed two clusters of activation in the left inferior frontal gyrus, in both a dorsal (pars triangularis) region (Table 2, Fig. 1A) and ventral (pars-orbitalis) region. Activation in these frontal regions has previously been attributed to working memory processes involved in $n$-back tasks similar to the one employed here (Owen, 1997), to phonological processes that contribute to word identification (Fiebach et al., 2002; Poldrack et al., 2001) or to processes of semantic selection and/or retrieval (Thompson-Schill, D'Esposito, Aguirre, \& Farah, 1997; Wagner, Pare-Blagoev, Clark, \& Poldrack, 2001). These activations fall between those regions that would be described as either clearly phonological or semantic in prior work (Devlin, Matthew, \& Rushworth, 2003; Poldrack et al., 1999) and therefore cannot adjudicate among these accounts of frontal contributions to language processing. Instead, our goal was to investigate whether processes involved in the comprehension of written words differentiate between words with varying linguistic properties, consistent with the neuropsychological data reviewed earlier. We will therefore focus on contrasts between the four groups of words with different morphological and syntactic properties.

\subsection{Morphological effects}

The comparison of responses to morphologically simple and complex words (collapsed over syntactic class) failed to show any voxel that responded differently to these two groups of items, either as an elevated or reduced response to complex words, even at a lenient uncorrected threshold $(p<.001)$. Although a smattering of voxels showed a difference between simple and complex words at a more liberal threshold $(p<.01$ uncorrected) we do not report or interpret these differences. It is a near certainty that voxels reaching this threshold are false-positives since there are over 160,000 comparisons in this analysis. The contrast between simple and complex words collapses over two distinct types of complex words: derivational and inflectional morphology. While the nature of the linguistic distinction between these different types of complex word is open to debate (one definition is that inflectional morphology does not change word class or meaning, Bybee, 1985), it is often assumed that inflectional morphology provides a more paradigmatic example of grammatically complex forms which are decomposed during processing (Caramazza et al., 1988). Furthermore, there is greater neuropsychological evidence to suggest dissociations involving inflectional rather than derivational morphology (e.g., Marslen-Wilson \& Tyler, 1997; Tyler \& Ostrin, 1994), although some behavioural investigations have shown parallel effects for derivations and inflections (e.g. Rueckl \& Raveh, 2000). These findings motivate a test for differences between derivational and inflectional morphology. In the context of this experiment, an interaction between syntactic class and morphological complexity is of interest. This is the contrast of (inflected verbs-simple verbs) vs (derived nouns/adjectives-simple nouns/adjectives) and vice-versa, testing for additional activation specific to inflected or derived words.

The interaction between morphological complexity and syntactic class failed to reach a corrected level of significance in any voxel. In testing for additional activation in response to inflectional morphology, no voxels reached an uncorrected threshold $(p<.001)$. However, the reverse contrast revealed a reliable interaction in two 
small clusters of voxels (10 and 2 voxels respectively) in the left insula $(x=-30, y=-6, z=+18, Z=3.83)$ and in left anterior frontal cortex $(x=-27, y=48, z=-12$; $Z=3.17$ ) suggesting a difference between inflectional and derivational morphology. Examination of the mean parameter estimates in these voxels however, showed a profile inconsistent with a morphological interpretation (see Fig. 1B for the response profile in the left insula) since they show an elevated response to simple verbs over simple nouns and adjectives (reaching $p<.1$ in a paired $t$ test in both peak voxels) that was absent in the comparison of inflected and derived words $(p>1)$. Evidence from neuropsychology and functional imaging has linked the insula to processes involved in articulation and phonological generation (Dronkers, 1996; Fiebach et al., 2002). While the precise function of the anterior frontal region remains unclear (Christoff \& Gabrieli, 2000), activation in similar regions has been observed in semantic decision making tasks (Scott, Leff, $\&$ Wise, 2003; Sharp, Scott, \& Wise, 2004). It is therefore possible that these interactions reflect some unmatched phonological or semantic properties of our stimulus materials. While this explanation remains tentative, however, the form of this interaction (and the small size of these effects) provides little support for any additional neural process involved in reading single, morphologically complex words.

Further contrasts were conducted to test for simple effects of morphological complexity for verbs and nouns/adjectives separately. These also failed to reveal any reliable activation specific to morphologically complex words. The implications of this lack of a significant effect of morphological complexity on accounts of lexical processing which invoke additional processes of morphological decomposition will be elaborated in the discussion section.

\subsection{Syntactic class effects}

We tested for differences between the neural response to verbs (both inflected and simple) and nouns/adjectives (simple and derived words). This contrast revealed a cluster of voxels in the left posterior middle temporal gyrus (MTG $x=-54, y=-48, z=-6, Z=4.94$, $p<.05$ FDR corrected) which showed a significantly elevated response to verbs (see Fig. 1A). The response profile of this voxel (shown in Fig. 1C) confirms that the elevated response is observed for both inflected and uninflected verbs (the contrast between nouns/adjectives and verbs reaches $p<.025$ for complex and simple items when considered separately), with no main effect or interaction with morphological complexity at even an uncorrected level of significance $(p>.05)$. Three further clusters of 15 voxels or more showed significant additional activation for verbs at an uncorrected threshold, in left posterior superior temporal sulcus (STS $x=-54$, $y=-36, z=+21, Z=3.54, p<.001)$ in the parahippocampal gyrus $(x=-21, y=-36, z=+3, Z=3.95$, $p<.001)$ and in the caudate $(x=-3, y=+9, z=-6$, $Z=3.41, p<.001)$. No voxel showed additional activation in the reverse contrast (i.e., elevated activation for nouns and adjectives) at $p<.001$ uncorrected.

This main area of additional activation for verbs in the posterior middle temporal gyrus falls within a single filter width (i.e., $12 \mathrm{~mm}$ ) of a number of other activations reported previously for verbs. For instance, an early PET study (Martin, Haxby, Lalonde, Wiggs, \& Ungerleider, 1995) showed activation in an overlapping region when participants generated verbs in response to line-drawings of objects (compared to generating colour names). Similar posterior MTG activations for verbs compared to nouns have also been reported in a number of other studies (Grezes \& Decety, 2002; Kable et al., 2002; Perani et al., 1999; Warburton et al., 1996).

\subsection{Action post-test and correlational fMRI analysis}

One important point is that (as for other functional neuroimaging studies) these results do not exclude the possibility that this posterior middle temporal region is involved in cognitive processes that are not verb specific. For instance, there is considerable overlap between the activation that we observed in the current study and brain regions that are activated in recognizing pictures of tools and other manipulable objects (Devlin et al., 2002; Martin, Wiggs, Ungerleider, \& Haxby, 1996). Studies of action observation and imitation have also reported activation of a similar region of posterior middle temporal gyrus (Grezes \& Decety, 2001). These results are important for the interpretation of the current study, since it is likely that more verbs describe actions than do nouns and adjectives.

To assess the strength of 'action-association' for each of the 288 words in our study we conducted a rating test with 16 participants from the same subject population, each of whom was asked to rate whether each word describes an action made by the body, or an object that is commonly associated with an action made by the body on a 7-point likert scale (where 7 indicated a strong action association). As expected, verbs received higher average ratings than nouns and adjectives (4.93 compared to $2.58, p<.001)$. The difference between morphologically simple and complex words was less marked (simple = 3.53, complex $=3.98$, though still significant $p<.05$ ). Although the strength of action associations clearly differentiates verbs and nouns, there is overlap in the ratings assigned to items in the different groups, with nouns like dancer and adjectives like stubborn receiving higher ratings than verbs like corrode, or presume.

We therefore conducted a further analysis of the imaging data in which all word events were modelled as a single type (no longer distinguishing between nouns 
and verbs), with action ratings entered as a covariate (a 'parametric modulator' in the SPM software, Buchel, Holmes, Rees, \& Friston, 1998). This analysis provides a test of whether the posterior middle-temporal activation is predicted by the strength of action association for each word. Mean parameter estimates (correlation-coefficients) from each subject were entered into randomeffects analysis as before, which showed that a reliable positive correlation could be observed within the posterior temporal region that responded to verbs. Within a region of interest based on areas activated for verbs over nouns, two left temporal lobe clusters show a correlation between activation and action ratings at a (small-volume) corrected level of significance (Worsley et al., 1996), in STS $(x=-57, y=-39, z=+24, Z=3.33$, $p<.05$ corrected) and in MTG $(x=-54, y=-54$, $z=-3, Z=3.29, p<.05$ corrected).

This analysis demonstrates that two alternative hypotheses can explain the observed response in the posterior middle temporal gyrus. To assess whether differences in syntactic class or action-association account for the observed variance in this temporal lobe response we performed a further analysis in which both syntactic class (verbs vs nouns/adjectives) and actionassociation ratings were entered as a parametric modulator to this single event-type. Due to a limitation of the SPM software, it is not possible to perform partial correlation analyses to determine whether one of these two factors is the better predictor of activation in this region. However, an analysis in which both variables are entered simultaneously indicates whether there is unique variance accounted for by either syntactic class or action-ratings alone. In this analysis, a region of the posterior superior temporal sulcus that responded to verbs showed a reliable correlation with action ratings, even when syntactic class effects were also modelled $(x=-54$, $y=-39, z=+21, Z=3.33, p<.05$ small-volume corrected). Thus, at least one of the temporal lobe regions which shows greater activation for verbs compared to nouns and adjectives is responding to semantic rather than the syntactic properties of our items.

\section{Discussion}

This study has demonstrated robust activation of frontal and temporal lobe regions in a task requiring semantic processing of single words by comparison with a well matched baseline. In comparisons between different classes of words, a reliable increase in activation for verbs was observed in a posterior middle-temporal gyrus region, replicating previous findings in the literature (Kable et al., 2002; Perani et al., 1999). Post hoc analyses suggest that this increased activation for verbs could arise either from an elevated response to the syntactic category of verbs, or as a response to a specific semantic property of some words (i.e., their association with actions). Since these two properties are confounded in the materials for the present study we are at present unable to distinguish between these two explanations.

The anatomical proximity of the posterior temporal region that responds to verbs to regions that respond in a specific fashion to pictures of tools (compared to other artefacts, see Devlin et al., 2002) and in action observation and imitation (Grezes \& Decety, 2001) suggests that semantic (action associations) rather than syntactic properties of verbs may be useful in interpreting this activation. However, further experiments to contrast action and non-action verbs would be required if we are to distinguish these two hypotheses with any certainty. Future investigations of verb and noun processing, both in neuroimaging and neuropsychology should similarly consider whether semantic rather than grammatical differences between verbs and nouns might be able to explain neural dissocations that are apparent for these items.

In contrast to this positive result for verbs there was no evidence of any difference in activation for morphologically simple and complex words, despite activation in relevant regions of the left inferior frontal gyrus in contrasts with the letter-string baseline. While inferences based on the absence of an effect must be limited, some tentative conclusions are appropriate. On the basis of the positive result for verbs compared to nouns, it is not the case that our study lacked the power to detect activation differences between specific classes of words. As can be seen in Fig. 1C, the differential response to verbs is of smaller magnitude than the difference between words and rest, but is nonetheless extremely reliable and reaches a corrected level of significance. If effects of morphological complexity did arise in the present study, they must have been of substantially smaller magnitude or been more variable (in size or location) between individuals.

What then can we conclude from the absence of morphological effects in this study? Other studies that have imaged neural responses during inflection and derivation generation tasks (Beretta et al., 2003; Jaeger et al., 1996; Marangolo et al., 2003) have reported activation increases associated with morphological operations. Frontal and temporal activations specific to inflected items have also been observed in a recent neuroimaging study in which participants were required to make phonological judgements on regular-, irregularand pseudo-inflected items (Marslen-Wilson, Stamatakis, Post, Randall, \& Tyler, 2003, see also Tyler et al., 2002) and in a study of semantic judgements made on inflected verbs and nouns (Tyler, Bright, Dick, \& Stamatakis, in press). Our results do not necessarily contradict these findings, but suggest that task-specific as well as linguistic factors may be important in explaining the presence or absence of morphological effects in 
particular functional imaging studies. If a task requires it, participants are clearly able to invoke overt morphological processes (such as decomposing jumping into jump + ing, or generating the past-tense jumped from the stem jump). However, brain regions activated for these tasks do not necessarily reflect processes that are also involved in on-line language comprehension and production. Although not all studies reporting morphological effects use overtly morphological tasks (e.g., Laine et al., 1999; Tyler et al., in press), the present lack of effects suggests that researchers need to be generally cautious about the possible implications of their results for more natural language use.

In the synonym monitoring task used here, overt processes of decomposition are not explicitly required for adequate task performance. One question is whether behavioural evidence of morphological decomposition would be expected in this task. Although the relevant investigations (using frequency measures, or priming) have not been conducted, apparent morphological effects have been observed in other behavioural tasks such as reading aloud (Rastle et al., 1999) or lexical decision (Baayen, Dijkstra, \& Schreuder, 1997; Marslen-Wilson et al., 1994; Taft, 1979) which, in common with synonym monitoring, do not require overt morphological operations. Indeed, evidence for morphological decomposition can even be obtained from experiments in which only monomorphemic words are presented to participants (see, for example, Ford, Davis, \& MarslenWilson, 2003; Schreuder \& Baayen, 1997). Thus, behavioural evidence for morphological decomposition does not depend on task situations in which morphological processes are explicitly demanded. It remains to be seen whether evidence for specific processes of decomposition can be obtained in analogous neuroimaging studies. Until these kinds of methodological questions are resolved, it remains difficult to use neuroimaging data to adjudicate between competing accounts of the functional and neural correlates of morphological complexity including distributed connectionist accounts in which decomposition arises from overlapping representations of morphologically related forms and where no specific neural mechanisms is required to handle this process (e.g. Davis, van Casteren, \& Marslen-Wilson, 2003; Plaut \& Gonnerman, 2000; Rueckl \& Raveh, 1999).

\section{Conclusions}

The results of this study have demonstrated additional activation for verbs (compared to nouns and adjectives) in a region of posterior middle temporal gyrus previously activated in other studies of verb processing. Post hoc analyses show that increased activation for verbs may arise from a response to a specific semantic property of verbs (i.e., their association with actions), consistent with other studies that show activation in the same temporal lobe region for the recognition of tools (Devlin et al., 2002) and for action observation/imitation (Grezes \& Decety, 2001). This result suggests a possible role for semantic variables in explaining neural dissociations for verbs compared to other word classes, which should be considered in future neuroimaging and neuropsychological studies.

\section{Appendix A}

Materials used in this experiment are shown in the blocks of 6 items that were presented to participants, divided into the four conditions.

\begin{tabular}{|c|c|}
\hline Inflected verbs & $\begin{array}{l}\text { clench, starve, applaud, condemn, } \\
\text { diagnose, pronounce; drench, pursue, } \\
\text { presume, swallow, dispense, } \\
\text { embarrass; contradict, freeze, travel, } \\
\text { portray, commence, announce; } \\
\text { cavort, stroll, forfeit, tremble, } \\
\text { paralyse, sprinkle; grovel, plunge, } \\
\text { rummage, succumb, jettison, } \\
\text { persuade; pierce, disrupt, wriggle, } \\
\text { abandon, perceive, quench; consult, } \\
\text { assemble, salvage, cringe, shrivel, } \\
\text { construct; confide, attract, snatch, } \\
\text { clutch, comprehend, corrode; swerve, } \\
\text { predict, scream, screech, transmit, } \\
\text { supervise; astound, marvel, bounce, } \\
\text { sustain, ricochet, improvise; cleave, } \\
\text { conclude, grieve, stumble, scrounge, } \\
\text { scavenge; glisten, snivel, sneeze, } \\
\text { disturb, straddle, quadruple } \\
\text { groped, thwarted, fetches, bleeds, } \\
\text { flinging, wallowing; kneels, shunted, } \\
\text { quaking, tempted, flirting, prancing; } \\
\text { drowns, blinked, governs, borrowed, } \\
\text { snooping, ignoring; mourns, snoozed, } \\
\text { cheated, choking, grinding, obliges; } \\
\text { served, sculpts, chooses, scalded, } \\
\text { stealing, shrinking; raised, sniffed, } \\
\text { rouses, munches, swallowing, } \\
\text { squelching; teased, chirped, preaches, } \\
\text { spawning, chucking, throwing; solved, } \\
\text { flaunts, boasting, creates, scolded, } \\
\text { flushing; greets, swilling, trudged, } \\
\text { marched, wringing, launching; } \\
\text { follows, parried, browsing, winced, } \\
\text { flinches, churning; learns, teaches, } \\
\text { spanked, quoting, twirling, walloped; } \\
\text { spends, scuffed, scraped, seizes, } \\
\text { pouncing, clinching }\end{array}$ \\
\hline
\end{tabular}




\section{Appendix A. (continued)}

\begin{tabular}{|c|c|}
\hline $\begin{array}{l}\text { Simple nouns/ } \\
\text { adjectives }\end{array}$ & $\begin{array}{l}\text { quaint, menace, scandal, fatigue, } \\
\text { merchant, orthodox; strand, sorrow, } \\
\text { forlorn, lozenge, platform, placenta; } \\
\text { stubborn, squire, circuit, throng, } \\
\text { stamina, mediocre; ballot, grammar, } \\
\text { occult, grimace, succinct, bungalow; } \\
\text { shrewd, pastel, symptom, pilgrim, } \\
\text { portrait, miracle; sequel, nephew, } \\
\text { oblique, satchel, trombone, } \\
\text { somersault; chaste, virtue, mundane, } \\
\text { quarrel, cataract, utensil; grudge, } \\
\text { mayhem, turmoil, flannel, tranquil, } \\
\text { protocol; mosque, mortar, peculiar, } \\
\text { strange, sparrow, sonata; thorough, } \\
\text { stanza, tribute, tariff, mackerel, } \\
\text { haddock; verdict, trapeze, strict, severe, } \\
\text { minstrel, specimen; freight, gospel, } \\
\text { sincere, monarch, sovereign, charlatan }\end{array}$ \\
\hline $\begin{array}{l}\text { Derived nouns/ } \\
\text { adjectives }\end{array}$ & $\begin{array}{l}\text { lawful, heaviness, springy, keeper, } \\
\text { thoughtful, fitness; fiendish, swimmer, } \\
\text { worthy, singer, selfish, painful; } \\
\text { babyish, honesty, youngish, cooker, } \\
\text { killer, careless; calmness, longish, } \\
\text { boyish, dealer, payable, darkness; } \\
\text { warmish, talker, firmness, starry, } \\
\text { scratchy, player; richness, hellish, } \\
\text { healer, badness, cheerful, lovely; } \\
\text { bubbly, laughable, brutish, beastly, } \\
\text { helper, frankness; merciful, weaver, } \\
\text { stormy, sleepy, kindness, goodness; } \\
\text { readable, offender, guilty, dancer, } \\
\text { agreeable, smoker; chilly, coldness, } \\
\text { freakish, hunter, tricky, valuable; } \\
\text { lender, traceable, girlish, runner, } \\
\text { illness, injury; lonely, vagueness, } \\
\text { pinkish, employer, manager, openness }\end{array}$ \\
\hline
\end{tabular}

Pairs of words that formed synonym paris are emphasised.

\section{References}

Baayen, R. H., Dijkstra, T., \& Schreuder, R. (1997). Singulars and plurals in Dutch: Evidence for a parallel dual-route modes. Journal of Memory and Language, 37(1), 94-117.

Baayen, R. H., Pipenbrook, R., \& Guilikers, L. (1995). The celex lexical database (CD-ROM) (Version v2.5). Philadelphia, PA: Linguistic Data Consortium, University of Pennsylvania.

Beretta, A., Campbell, C., Carr, T. H., Huang, J., Schmitt, L. M., Christianson, K., \& Cao, Y. (2003). An ER-fMRI investigation of morphological inflection in German reveals that the brain makes a distinction between regular and irregular forms. Brain and Language, 85(1), 67-92.

Bird, H., Howard, D., \& Franklin, S. (2000). Why is a verb like an inanimate object? Grammatical category and semantic category deficits. Brain and Language, 72(3), 246-309.
Bird, H., Lambon Ralph, M. A., Seidenberg, M. S., McClelland, J. L., \& Patterson, K. (2003). Deficits in phonology and past-tense morphology: What's the connection? Journal of Memory and Language, 48, 502-526.

Brett, M., Leff, A. P., Rorden, C., \& Ashburner, J. (2001). Spatial normalization of brain images with focal lesions using cost function masking. Neuroimage, 14(2), 486-500.

Buchel, C., Holmes, A. P., Rees, G., \& Friston, K. J. (1998). Characterizing stimulus-response functions using nonlinear regressors in parametric fMRI experiments. Neuroimage, 8(2), 140-148.

Bybee, J. L. (1985). Morphology: A study of the relation between meaning and form. Philadelphia, PA: John Benjamins.

Caramazza, A., \& Hillis, A. E. (1991). Lexical organization of nouns and verbs in the brain. Nature, 349(6312), 788-790.

Caramazza, A., Laudanna, A., \& Romani, C. (1988). Lexical access and inflectional morphology. Cognition, 28(3), 297-332.

Christoff, K., \& Gabrieli, J. D. E. (2000). The frontopolar cortex and human cognition: Evidence for a rostrocaudal hierarchical organization within the human prefrontal cortex. Psychobiology, 28(2), 168-186.

Cohen, L., Dehaene, S., Naccache, L., Lehericy, S., DehaeneLambertz, G., Henaff, M. A., \& Michel, F. (2000). The visual word form area: spatial and temporal characterization of an initial stage of reading in normal subjects and posterior split-brain patients. Brain, 123(Pt 2), 291-307.

Cohen, L., Lehericy, S., Chochon, F., Lemer, C., Rivaud, S., \& Dehaene, S. (2002). Language-specific tuning of visual cortex? Functional properties of the visual word form area. Brain, $125(\mathrm{Pt}$ 5), 1054-1069.

Coltheart, M. (1981). The MRC psycholinguistic database. Quarterly Journal of Experimental Psychology, 33A, 497-505.

Damasio, A. R., \& Tranel, D. (1993). Nouns and verbs are retrieved with differently distributed neural systems. Proceedings of the National Academy of Science of the United States of America, 90(11), 4957-4960.

Davis, M. H., van Casteren, M., \& Marslen-Wilson, W. D. (2003). Frequency effects in processing inflected Dutch nouns: A distributed connectionist account. In R. H. Baayen \& R. Screuder (Eds.), Morphological Structure in Language Processing (pp. 427-462). Berlin: Mouton de Gruyter.

Devlin, J. T., Matthew, P. M., \& Rushworth, M. F. S. (2003). Semantic processing in Broca's area: A combined fMRI and TMS study. Journal of Cognitive Neuroscience, 15(1), 1-14.

Devlin, J. T., Russell, R. P., Davis, M. H., Price, C. J., Moss, H. E., Fadili, M. J., \& Tyler, L. K. (2002). Is there an anatomical basis for category-specificity. Semantic memory studies in PET and fMRI. Neuropsychologia, 40(1), 54-75.

Devlin, J. T., Russell, R. P., Davis, M. H., Price, C. J., Wilson, J., Moss, H. E., Matthews, P. M., \& Tyler, L. K. (2000). Susceptibility-induced loss of signal: comparing PET and fMRI on a semantic task. Neuroimage, 11(6 Pt 1), 589-600.

Dronkers, N. F. (1996). A new brain region for coordinating speech articulation. Nature, 384(6605), 159-161.

Fiebach, C. J., Friederici, A. D., Muller, K., \& von Cramon, D. Y. (2002). fMRI evidence for dual routes to the mental lexicon in visual word recognition. Journal of Cognitive Neuroscience, 14(1), $11-23$.

Ford, M., Davis, M. H., \& Marslen-Wilson, W. (2003). Morphology and frequency: contrasting methodologies. In R. H. Baayen \& R. Screuder (Eds.), Morphological structure in language processing (pp. 89-124). Berlin: Mouton de Gruyter.

Forster, K. I., \& Forster, J. C. (2003). DMDX: A windows display program with millisecond accuracy. Behavioral Research Methods, Instruments and Computers, 35(1), 116-124.

Friston, K. J., Fletcher, P., Josephs, O., Holmes, A., Rugg, M. D., \& Turner, R. (1998). Event-related fMRI: characterizing differential responses. Neuroimage, 7(1), 30-40. 
Genovese, C. R., Lazar, N. A., \& Nichols, T. (2002). Thresholding of statistical maps in functional neuroimaging using the false discovery rate. Neuroimage, $15(4), 870-878$.

Grezes, J., \& Decety, J. (2001). Functional anatomy of execution, mental simulation, observation, and verb generation of actions: a meta-analysis. Human Brain Mapping, 12(1), 1-19.

Grezes, J., \& Decety, J. (2002). Does visual perception of object afford action? Evidence from a neuroimaging study. Neuropsychologia, 40(2), 212-222.

Henson, R. N., Price, C. J., Rugg, M. D., Turner, R., \& Friston, K. J. (2002). Detecting latency differences in event-related BOLD responses: Application to words versus nonwords and initial versus repeated face presentations. Neuroimage, 15(1), 83-97.

Jaeger, J. J., Lockwood, A. H., Kemmerer, D. L., Van Valin, R. D., Jr, Murphy, B. W., \& Khalak, H. G. (1996). A positron emission tomographic study of regular and irregular verb morphology in English. Language, 72(3), 451-497.

Josephs, O., \& Henson, R. N. (1999). Event-related functional magnetic resonance imaging: Modelling, inference and optimization. Philosophical Transactions of the Royal Society London B Biological Sciences, 354(1387), 1215-1228.

Kable, J. W., Lease-Spellmeyer, J., \& Chatterjee, A. (2002). Neural substrates of action event knowledge. Journal of Cognitive Neuroscience, 14(5), 795-805.

Kotz, S. A., Cappa, S. F., von Cramon, D. Y., \& Friederici, A. D. (2002). Modulation of the lexical-semantic network by auditory semantic priming: An event-related functional MRI study. Neuroimage, 17(4), 1761-1772.

Laine, M., Rinne, J. O., Krause, B. J., Teras, M., \& Sipila, H. (1999). Brain activation during encoding of inflected words. Brain and Language, 69(3), 305-308.

Loftus, G. R., \& Masson, M. E. J. (1994). Using confidence-intervals in within-subject designs. Psychonomic Bulletin \& Review, 1(4), 476-490.

Longworth, C. (2002). Understanding the regular past tense in English: A cognitive neuroscience approach. Unpublished $\mathrm{PhD}$, Cambridge University, Cambridge, UK.

Marangolo, P., Incoccia, C., Pizzamiglio, L., Sabatini, U., CastriotaScanderbeg, A., \& Burani, C. (2003). The right hemisphere involvement in the processing of morphologically derived words. Journal of Cognitive Neuroscience, 15(3), 364-371.

Marangolo, P., Piras, F., Galati, G., \& Burani, C. (2003). Frontoparietal network involvement in the processing of derivational morphology: An fMRI study. Paper presented at the 3rd International Workshop on Morphological Processing. Aix-En-Provence, France.

Marchand, H. (1969). The categories and types of present-day English word-formation. Munich, Germany: Beck.

Marslen-Wilson, W. D., \& Tyler, L. K. (1997). Dissociating types of mental computation. Nature, 387(6633), 592-594.

Marslen-Wilson, W., Tyler, L. K., Waksler, R., \& Older, L. (1994). Morphology and meaning in the English mental lexicon. Psychological Review, 101(1), 3-33.

Marslen-Wilson, W., Stamatakis, E. A., Post, B., Randall, B., \& Tyler, L. K. (2003). Neural differentiation within the language system: The past tense. Poster presented at the 9th International Conference on Functional Mapping of the Human Brain, New York, NY, USA.

Martin, A., Haxby, J. V., Lalonde, F. M., Wiggs, C. L., \& Ungerleider, L. G. (1995). Discrete cortical regions associated with knowledge of color and knowledge of action. Science, 270(5233), 102-105.

Martin, A., Wiggs, C. L., Ungerleider, L. G., \& Haxby, J. V. (1996). Neural correlates of category-specific knowledge. Nature, 379(6566), 649-652.

Mechelli, A., Henson, R. N., Price, C. J., \& Friston, K. J. (2003). Comparing event-related and epoch analysis in blocked design fMRI. Neuroimage, 18(3), 806-810.
Owen, A. M. (1997). The functional organization of working memory processes within human lateral frontal cortex: The contribution of functional neuroimaging. European Journal of Neuroscience, 9, 1329-1339.

Perani, D., Cappa, S. F., Schnur, T., Tettamanti, M., Collina, S., Rosa, M. M., \& Fazio, F. (1999). The neural correlates of verb and noun processing. A PET study. Brain, 122(Pt 12), 2337-2344.

Pinker, S. (1999). Words and rules: The ingredients of language: Weidenfeld \& Nicholson.

Plaut, D. C., \& Gonnerman, L. M. (2000). Are non-semantic morphological effects incompatible with a distributed connectionist approach to lexical processing? Language and Cognitive Processes, 15(4-5), 445-485.

Poldrack, R. A., Wagner, A. D., Prull, M. W., Desmond, J. E., Glover, G. H., \& Gabrieli, J. D. (1999). Functional specialization for semantic and phonological processing in the left inferior prefrontal cortex. Neuroimage, 10, 15-35.

Poldrack, R. A., Temple, E., Protopapas, A., Nagarajan, S., Tallal, P., Merzenich, M., \& Gabrieli, J. D. E. (2001). Relations between the neural bases of dynamic auditory processing and phonological processing: Evidence from fMRI. Journal of Cognitive Neuroscience, 13(5), 687-697.

Polk, T. A., \& Farah, M. J. (2002). Functional MRI evidence for an abstract, not perceptual, word-form area. Journal of Experimental Psychology: General, 131(1), 65-72.

Price, C. J. (2000). The anatomy of language: Contributions from functional neuroimaging. Journal of Anatomy, 197(Pt 3), 335-359.

Price, C. J., \& Devlin, J. T. (2003). The myth of the visual word form area. Neuroimage, 19(3), 473-481.

Rastle, K., Davis, M. H., Tyler, L., \& Marslen-Wilson, W. (2000). Morphological and semantic effects in visual word recognition: A timecourse study. Language and Cognitive Processes, 15(4/5), 507-537.

Rastle, K., Tyler, L. K., \& Marslen-Wilson, W. (1999). Morphological impairment in acquired dyslexia: Distinguishing morphological, semantic and orthographic information. Brain and Language, 69(3), 308-311.

Rueckl, J. G., \& Raveh, M. (1999). The influence of morphological regularities on the dynamics of a connectionist network. Brain and Language, 68(1-2), 110-117.

Rueckl, J. G., \& Raveh, M. (2000). Equivalent effects of inflected and derived primes: Long term morphological priming in fragment completion and lexical decision. Journal of Memory and Language, $42,103-119$.

Schreuder, R., \& Baayen, R. H. (1997). How complex simple words can be. Journal of Memory and Language, 37(1), 118-139.

Scott, S. K., Leff, A. P., \& Wise, R. J. S. (2003). Going beyond the information given: a neural system supporting semantic interpretation. Neuroimage, 19(3), 870-876.

Shapiro, K., \& Caramazza, A. (2003). The representation of grammatical categories in the brain. Trends in Cognitive Science, 7(5), 201-206.

Sharp, D. J., Scott, S. K., \& Wise, R. J. (2004). Monitoring and the controlled processing of meaning: distinct prefrontal systems. Cereb Cortex, 14(1), 1-10.

Taft, M. (1979). Recognition of affixed words and the word frequency effect. Memory and Cognition, 7(4), 263-272.

Thompson-Schill, S., D’Esposito, M., Aguirre, G., \& Farah, M. (1997). Role of left inferior prefrontal cortex in retrieval of semantic knowledge: A reevaluation. Proceedings of the National Academy of Sciences of the United States of America, 94(26), 14792-14979.

Tyler, L. K., Bright, P., Dick, E., \& Stamatakis, E. (in press). Neural processing of nouns and verbs: the role of inflectional morphology. Neuropsychologia.

Tyler, L. K., deMornay-Davies, P., Anokhina, R., Longworth, C., Randall, B., \& Marslen-Wilson, W. D. (2002). Dissociations in processing past tense morphology: Neuropathology and behavioral studies. Journal of Cognitive Neuroscience, 14(1), 79-94. 
Tyler, L. K., \& Ostrin, R. K. (1994). The processing of simple and complex words in an agrammatic patient: Evidence from priming. Neuropsychologia, 32(8), 1001-1013.

Tyler, L. K., Russell, R., Fadili, J., \& Moss, H. E. (2001). The neural representation of nouns and verbs: PET studies. Brain, 124(Pt 8), $1619-1634$.

Ullman, M. T., Corkin, S., Coppola, M., Hickok, G., Crowden, J. H., Koroshetz, W. J., \& Pinker, S. (1997). A neural dissociation within language: Evidence that the mental dictionary is part of declarative memory and that grammatical rules are processed by the procedural system. Journal of Cognitive Neuroscience, 9(2), 266-276.

Ullman, M. T. (2001). A neurocognitive perspective on language: The declarative/procedural model. Nature Reviews Neuroscience, 2(10), $717-726$.
Wagner, A., Pare-Blagoev, E., Clark, J., \& Poldrack, R. (2001). Recovering meaning: Left prefrontal cortex guides controlled semantic retrieval. Neuron, 31(2), 329-338.

Warburton, E., Wise, R. J., Price, C. J., Weiller, C., Hadar, U., Ramsay, S., \& Frackowiak, R. S. (1996). Noun and verb retrieval by normal subjects Studies with PET. Brain, 119(Pt 1), 159-179.

Worsley, K. J., Marrett, S., Neelin, P., Vandal, A. C., Friston, K. J., \& Evans, A. C. (1996). A unified statistical approach for determining significant signals in images of cerebral activation. Human Brain Mapping, 4(58-83).

Xiong, J., Rao, S., Jerabek, P., Zamarripa, F., Woldorff, M., Lancaster, J., \& Fox, P. T. (2000). Intersubject variability in cortical activations during a complex language task. NeuroImage, 12(3), 326-339. 